\title{
PENCEGAHAN KARIES GIGI MELALUI PELATIHAN DETEKSI DINI KARIES GIGI DAN CARA MENYIKAT GIGI PADA KELOMPOK IBU DI DESA KALASEY KECAMATAN MANDOLANG KABUPATEN MINAHASA
}

\author{
Jeineke E. Ratuela ${ }^{1}$, Anneke A.Tahulending ${ }^{2}$, Ni Made Yuliana ${ }^{3}$, \\ 1)2)3), Jurusan Keperawatan Gigi Poltekkes Manado Jl.R.W Mongisidi Malalayang Manado
}

\begin{abstract}
ABSTRAK
Latar Belakang : Upaya pemeliharaan gigi salah satunya dengan melakukan deteksi dini karies gigi. Deteksi dini karies gigi perlu dilakukan untuk membatasi agar karies tidak berlanjut menjadi parah. Hal ini perlu mendapat perhatian dari orang tua khususnya ibu, terutama umur 6 sampai 9 tahun dimana umur 6 tahun gigi molar permanen sudah mulai tumbuh sehingga lebih rentan dan terlebih dahulu terkena karies. Umur 9 tahun merupakan periode gigi bercampur dimana jumlah gigi permanen dan gigi sulung dalam rongga mulut hampir sama yaitu 14 gigi permanen dan 10 gigi sulung. Tujuan : Untuk mengetahui pencegahan karies gigi melalui pelatihan deteksi dini tanda-tanda karies gigi dan cara menyikat gigi pada kelompok ibu di desa Kalasey Kecamatan Mandolang Kabupaten Minahasa. Metode : pengabdian.ini menggunakan metode desktiptif untuk menggambarkan pencegahan karies gigi melalui pelatihan deteksi dini karies gigi dan cara menyikat gigi pada kelompok ibu di desa Kalasey Kecamatan Mandolang Kabupaten Minahasa. Teknik pengambilan sampel yaitu Accidental sampling berjumlah $50 \mathrm{ibu}$ yang terpilih. Pengumpulan data menggunakan kuesioner. Hasil : responden sebelum diberikan pelatihan paling banyak memiliki pengetahuan cukup baik yaitu sebanyak $25(50 \%)$ responden, dan sesudah pelatihan paling banyak pada pengetahuan baik yaitu $41(82 \%)$ responden. Cara menyikat gigi responden sebelum dilakukan pelatihan paling banyak kurang baik yaitu 37 (74\%) responden, dan sesudah pelatihan meningkat menjadi $44(88 \%)$ responden. Kesimpulan : Berdasarkan hasil pengabdian masyarakat diperoleh kesimpulan bahwa ada peningkatan pengetahuan responden tentang deteksi dini tanda-tanda karies gigi, maupun cara menyikat gigi responden sebelum dan sesudah diberikan pelatihan
\end{abstract}

Kata Kunci: Pencegahahan karies gigi, Deteksi Dini Karies Gigi, Cara Menyikat Gigi.

\begin{abstract}
Background: One of the efforts to maintain teeth is by early detection of dental caries. Early detection of dental caries needs to be done to limit caries so that it does not progress to being severe. This needs attention from parents, especially mothers, especially those aged 6 to 9 years, where at 6 years old permanent molars have started to grow so that they are more susceptible to caries first. The age of 9 years is a mixed dentition period where the number of permanent and primary teeth in the oral cavity is almost the same, namely 14 permanent teeth and 10 primary teeth. Objective: To determine the prevention of dental caries through training on early detection of signs of dental caries and how to brush teeth in a group of women in Kalasey village, Mandolang sub-district, Minahasa district. Method: This service uses descriptive method to describe the prevention of dental caries through training on early detection of dental caries and how to brush teeth in a group of women in Kalasey village, Mandolang District, Minahasa Regency. The sampling technique was Accidental sampling, amounting to 50 selected mothers. Data collection using a questionnaire. Results: respondents before being given training had a fairly good knowledge at most, namely 25 $(50 \%)$ of respondents, and after training the most on good knowledge were $41(82 \%)$
\end{abstract}


respondents. The method of brushing the teeth of the respondents before the training was carried out was at most poor, namely $37(74 \%)$ of respondents, and after the training increased to $44(88 \%)$ of respondents. Conclusion: Based on the results of community service, it was concluded that there was an increase in respondents' knowledge about early detection of signs of dental caries, as well as how to brush their teeth before and after being given training.

Keywords: Prevention of dental caries, Early Detection of Dental Caries, Method of Brushing Teeth.

\section{PENDAHULUAN}

Kesehatan gigi dan mulut merupakan bagian dari kesehatan tubuh yang tidak dapat dipisahkan satu sama lain sebab kesehatan gigi dan mulut akan mempengaruhi kesehatan tubuh secara keseluruhan. Gigi merupakan salah satu bagian tubuh yang berfungsi untuk mengunyah, berbicara dan mempertahankan bentuk wajah. Mengingat kegunaannya yang demikian penting maka penting untuk menjaga dan memelihara sedini mungkin agar dapat bertahan lama dalam rongga mulut .

Upaya pemeliharaan gigi salah satunya dengan melakukan deteksi dini karies gigi. Deteksi dini karies gigi perlu dilakukan untuk membatasi agar karies tidak berlanjut menjadi parah. Hal ini perlu mendapat perhatian dari orang tua khususnya ibu, terutama umur 6 sampai 9 tahun dimana umur 6 tahun gigi molar permanen sudah mulai tumbuh sehingga lebih rentan dan terlebih dahulu terkena karies. Umur 9 tahun merupakan periode gigi bercampur dimana jumlah gigi permanen dan gigi sulung dalam rongga mulut hampir sama yaitu 14 gigi permanen dan 10 gigi sulung. ${ }^{2}$ Karies gigi adalah suatu penyakit jaringan gigi yang ditandai dengan kerusakan jaringan, dimulai dari permukan gigi (pit, fissure dan daerah interproximal) dan meluas kearah pulpa. Karies gigi merupakan penyakit gigi yang paling banyak ditemukan, meliputi semua usia dan lapisan masyarakat. ${ }^{3}$ Pemberdayaan masyarakat bidang kesehatan gigi dan mulut merupakan salah satu cara untuk mengatasi karies gigi diantaranya dengan memberdayakan masyarakat untuk memotivasi dan mempengaruhi masyarakat dalam menjaga kesehatan gigi sehingga terhindar dari karies gigi. Kegiatan dapatt dilakukan lebih diarahkan pada pelayanan promotif, preventif dan rujukan kesehatan gigi dan mulut yang dilakukan pada upaya kesehatan berbasis masyarakat diantaranya posyandu dengan sasaran kelompok resiko tinggi meliputi anak usia balita, anak usia sekolah pendidikan dasar, ibu hamil dan menyusui, dan kelompok usia lanjut. ${ }^{4}$ Salah satu upaya pemerintah untuk meningkatkan pembangunan kesehatan terutama kesehatan gigi dan mulut melalui Upaya Kesehatan Gigi Masyarakat (UKGMD) adalah suatu pendekatan edukatif yang bertujuan untuk meningkatkan kemampuan dan peran serta masyarakat dalam pemeliharaan kesehatan gigi, dengan mengintegrasikan upaya promotif, preventif kesehatan gigi. Kegiatan ini perlu dilakukan untuk meningkatkan kesadaran, kemauan, kemampuan dan peran serta masyarakat/keluarga dalam pemeliharaan kesehatan gigi. 4 
Berdasarkan Riset Kesehatan Dasar (Riskesdas) tahun 2013 menunjukkan bahwa penduduk yang berperilaku benar dalam merawat gigi yaitu $76,6 \%$, sedangkan penduduk yang bermasalah dengan kesehatan gigi sebanyak 25,9\%, namun penduduk yang mempunyai kesadaran untuk merawat gigi hanya $31,1 \%$ dan penderita yang tidak mau merawat giginya sebanyak $68,9 \%$, dan kecenderungan indeks DMF-T sebanyak 4,6, sedangkan di Propinsi Sulawesi Utara, kecenderungan DMF-T sebanyak 5,4. ${ }^{5}$

Kelompok ibu adalah individu yang dipilih, termasuk didalamnya kader kesehatan, memiliki kemampuan untuk mengikuti kegiatan pelatihan dengan baik, sehingga dapat membantu dalam upaya peningkatan kualitas kesehatan gigi dan mulut terhadap diri sendiri, teman, keluarga serta lingkungannya. Melalui pelatihan ini kelompok ibu dapat membagi dan meneruskan pengetahuan serta ketrampilan yang diperoleh kepada teman, keluarga dan masyarakat sekitarnya tentang kesehatan gigi dan mulut serta menjadi penggerak hidup sehat di rumah dan lingkungannya.

Variabel pada pengabdian ini tentang pencegahan karies gigi melalui pelatihan deteksi dini karies gigi dan cara menyikat gigi pada kelompok ibu di desa Kalasey Kecamatan Mandolang Kabupaten Minahasa. Populasi dalam penelitian ini yaitu seluruh kelompok ibu yang terpilih (ibu-ibu desa setempat dan kader kesehatan) berjumlah 50 orang.

\section{HASIL}

1. Distribusi karakteristik responden penelitian dapat dilihat pada tabel 1

Tabel 1. Karakteristik Responden

\begin{tabular}{lccc}
\hline \multicolumn{2}{c}{$\begin{array}{c}\text { Karaktersistik } \\
\text { Responden }\end{array}$} & Frekuensi & \% \\
\hline Tingkat & SMP & 10 & 20,3 \\
Pendidikan & SMA & 38 & 76.0 \\
Ibu & PT & 2 & 4.0 \\
& Total & $\mathbf{5 0}$ & $\mathbf{1 0 0 . 0}$ \\
\hline Pekerjaan & PNS & 5 & 10.0 \\
Ibu & Swasta & 14 & 28.0 \\
& IRT & 29 & 58.0 \\
& Pensiunan & 2 & 4.0 \\
& Total & $\mathbf{5 0}$ & $\mathbf{1 0 0 . 0}$ \\
\hline
\end{tabular}

Distribusi karakteristik responden berdasarkan tingkat pendidikan menunjukkan bahwa tingkat pendidikan responden terbanyak tamatan Sekolah Menengah Atas (SMA) yaitu 38 responden (76\%) dan paling sedikit tamatan Perguruan Tinggi (PT) yaitu 2 responden (4\%). Distribusi karakteristik responden berdasarkan jenis pekerjaan menunjukkan bahwa jenis pekerjaan responden terbanyak Ibu Rumah Tangga (IRT) yaitu 29 responden $(58 \%)$ dan paling sedikit Pensiunan yaitu 2 responden (4\%).

2. Distribusi pengetahuan responden sebelum (Pre Test) dan sesudah (Post Test) pelatihan tentang deteksi dini karies gigi pada kelompok ibu di desa Kalasey Kecamatan Mandolang Kabupaten Minahasa. 


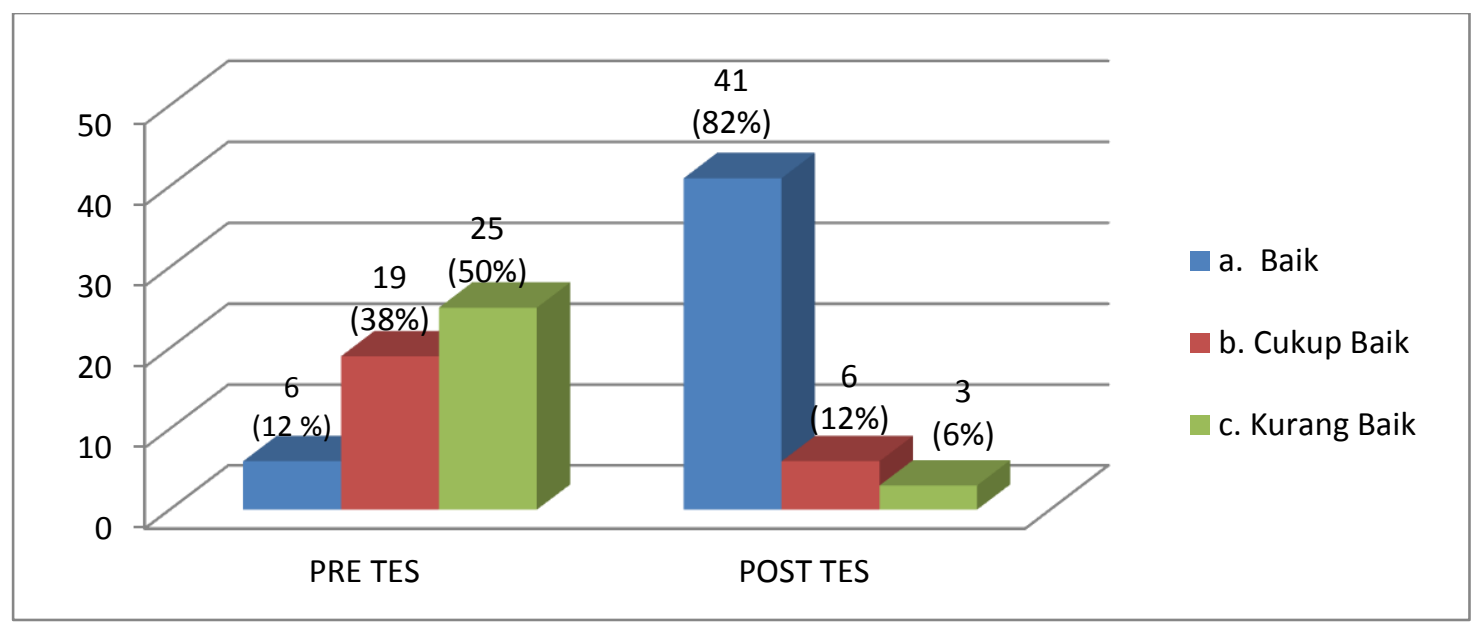

Gambar 1. Distribusi Pengetahuan Responden Sebelum (Pre Test) dan Sesudah (Post Test) Pelatihan tentang Deteksi Dini Karies Gigi pada Kelompok Ibu di Desa Kalasey Kecamatan Mandolang Kabupaten Minahasa.

Berdasarkan gambar 1, dapat dilihat bahwa pengetahuan responden sebelum (Pre Test) pelatihan paling banyak berpengetahuan cukup baik yaitu sebanyak $25(50 \%)$ responden, dan paling sedikit pada pengetahuan baik $6 \quad(12 \%)$ responden. Pengetahuan responden sesudah (Post Test) pelatihan paling banyak pada pengetahuan baik yaitu sebanyak $41(82 \%)$ responden, dan paling sedikit pada pengetahuan kurang baik sebanyak $3(6 \%)$ responden

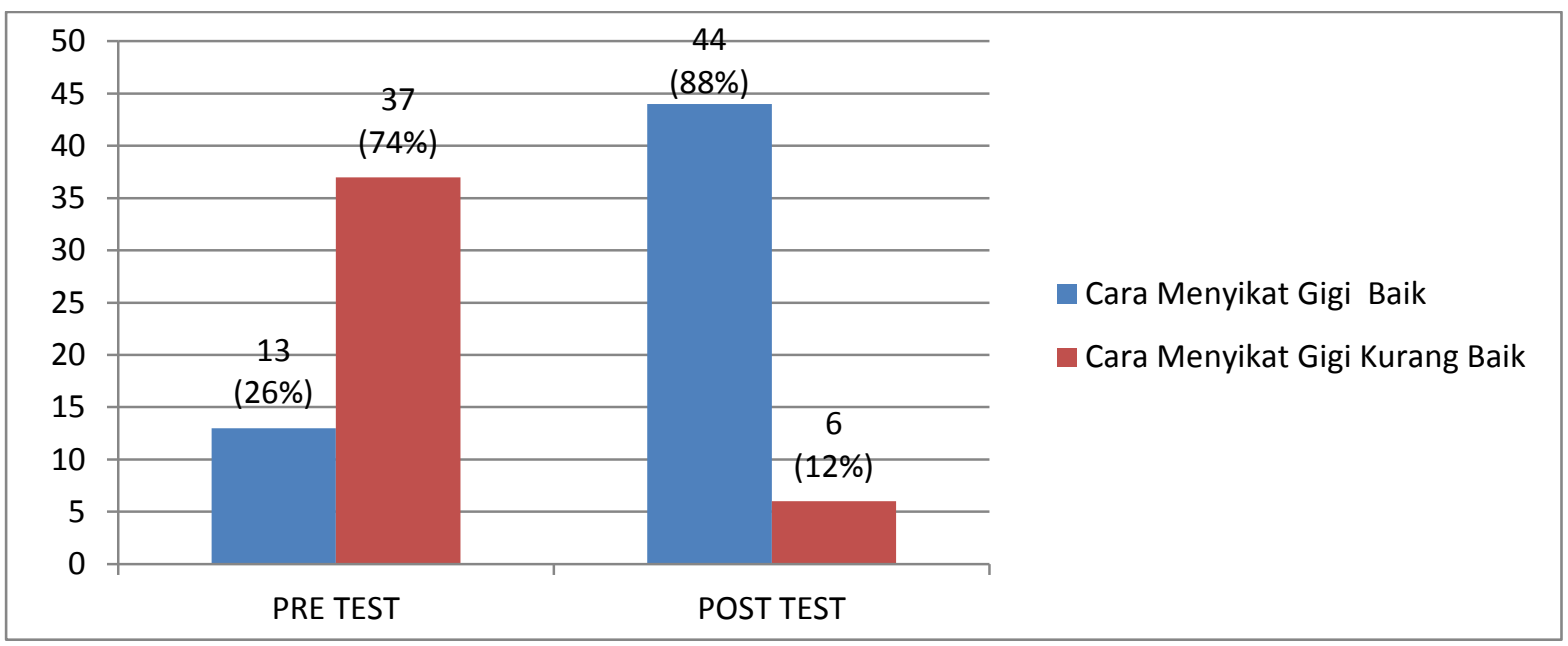

Gambar 2. Distribusi Cara Menyikat Gigi Responden Sebelum (Pre Test) dan Sesudah (Post Test) Pelatihan Cara Menyikat Gigi pada Kelompok Ibu di Desa Kalasey Kecamatan Mandolang

Berdasarkan gambar 2, dapat dilihat bahwa cara menyikat gigi responden sebelum (Pre Test) pelatihan tentang cara menyikat gigi paling banyak kurang baik yaitu sebanyak $37(74 \%)$ responden, dan sesudah (Post Test) meningkat menjadi 44 $(88 \%)$ responden. 


\section{PEMBAHASAN}

Salah satu strategi untuk memperoleh perubahan perilaku menurut WHO yang dikutip oleh Notoadmojo' 2013 adalah dengan pemberian informasi untuk meningkatkan pengetahuan sehingga menimbulkan kesadaran dan dapat dilakukan dengan pemberian pelatihan Pengetahuan adalah hasil tahu dari manusia yang terdiri dari sejumlah faktor dan teori yang memungkinkan seseorang untuk dapat memecahkan masalah yang dihadapinya. Pengetahuan diperoleh baik dari pengalaman langsung maupun dari pengalaman orang lain. Pengetahuan merupakan hasil penginderaan terhadap objek tertentu. ${ }^{6}$

Pengetahuan diperoleh sebagai akibat stimulus yang ditangkap pancaindra. Pengetahuan bisa diperoleh secara alami maupun secara terencana yaitu melalui proses pendidikan. Pengetahuan merupakan ranah yang sangat penting untuk terbentuknya tindakan, sama halnya dengan sikap dan norma positif atau negatif yang terjadi pada diri seseorang akan menyebabkan niat untuk bertindak. ${ }^{6}$ Pengetahuan ibu tentang kesehatan gigi akan sangat menentukan status kesehatan gigi anaknya kelak. Namun pengetahuan saja tidak cukup, perlu diikuti dengan sikap dan tindakan yang tepat. ${ }^{5}$

Berdasarkan hasil pengabdian masyarakat tentang pengetahuan responden sebelum (Pre Test) pelatihan deteksi dini tanda-tanda karies gigi diperoleh sebanyak $25 \quad(50 \%)$ responden yang berpengetahuan kurang baik, dan sesudah (Post Test) pengetahuan responden meningkat menjadi baik sebanyak 41 (88\%). Hal ini menunjukkan bahwa terdapat peningkatan pengetahuan setelah dilakukan pelatihan tentang deteksi dini karies gigi pada kelompok ibu di desa Kalasey Kecamatan Mandolang
Kabupaten Minahasa. Sebagian besar (76 $\%)$ responden memilik pendidikan SMA, dan 2 responden berpendidikan Perguruan Tinggi. Tingkat pendidikan berhubungan dengan tingkat pengetahuan. ${ }^{7}$ Orang dengan pendidikan lebih tinggi biasanya memiliki pengetahuan yang lebih baik sehingga keberhasilan pelatihan didukung juga oleh tingkat pendidikan dari responden. Meningkatnya pengetahuan tentang deteksi dini karies gigi responden karena masing-masing responden juga melakukan pemeriksaan secara langsung pada anak sekolah. Dengan mempraktekkan secara langsung bagaimana cara melakukan deteksi dini tanda-tanda karies gigi memungkinkan responden untuk mengingat setiap materi yang diberikan sehingga dapat meningkatkan pengetahuan. pengetahuan merupakan hasil dari tahu, dan ini terjadi setelah orang melakukan pengindraan terhadap suatu objek tertentu. ${ }^{6}$ Sesuai penelitian Sumerti 2013 tentang faktorfaktor yang berhubungan dengan perilaku ibu dalam mendeteksi karies gigi pada anak Balita di Kecamatan Kuta Utara menunjukkan bahwa pengetahuan responden berkategori baik sebanyak 73,4 $\%$ dan kurang baik sebanyak 26,6 \%. ${ }^{7}$

Berdasarkan hasil pengabdian masyarakat tentang cara menyikat gigi responden sebelum (Pre Test) pelatihan tentang cara menyikat gigi paling banyak kurang baik yaitu sebanyak 37 (74\%) responden, dan sesudah (Post Test) meningkat menjadi $44(88 \%)$ responden. Keterampilan responden dalam mempraktekkan cara-cara menyikat gigi yang baik dan benar menunjukkan bahwa responden memahami dengan benar materi pelatihan yang telah disampaikan sehingga mampu untuk mempraktekkan. Terjadi peningkatan cara-cara menyikat gigi 
menjadi baik disebabkan karena masingmasing responden juga mempraktekkan langsung pada siswa sekolah dasar sehingga memungkinkan responden mengingat tahap demi tahap cara-cara menyikat gigi yang baik dan benar sehingga responden menjadi terampil. Sesuai dengan pelatihan kader Posyandu yang dilakukan Arini, dkk (2018) di Kecamatan Marga Kabupaten Tabanan dimana cara menyikat gigi yang benar yang dimilki oleh Kader Posyandu Desa Kukuh juga mengalami peningkatan dengan baik. Setelah mendapat pelatihan terjadi peningkatan sebanyak $35(100 \%)$ kader terampil menggosok gigi dengan cara yang benar. ${ }^{9}$

\section{KESIMPULAN}

Berdasarkan hasil pengabdian masyarakat diperoleh kesimpulan bahwa setelah pelatihan maka tingkat pengetahuan responden tentang deteksi tanda-tanda karies gigi meningkat menjadi baik sebanyak 41 (82\%). Cara-cara menyikat gigi responden juga mengalami peningkatan sesudah pelatihan meningkat menjadi $44(88 \%)$ responden.

\section{SARAN}

Setelah melaksanakan pengabdian masyarakat, maka pengabdi dapat memberikan saran yaitu :

1. Bagi Ibu

a. Memperhatikan kesehatan gigi anak dalam hal ini pertumbuhan gigi tetap yang mulai tumbuh pada usia 6 tahun

b. Mengingatkan anak untuk menjaga kesehatan gigi dengan menyikat gigi yang baik setiap hari sesudah makan dan memperhatikan makanan yang dikonsumsi anak baik di rumah maupun disekolah

c. Jika menemukan tanda-tanda karies gigi segera ke poliklinik gigi untuk mendapatkan perawatan lebih lanjut

d. Meneruskan ilmu yang telah diperoleh kepada anak maupun keluarga serta lingkungan sekitarnya.

2. Bagi dosen dan calon dosen selanjutnya agar dapat melakukan pengabdian berkaitan dengan cara-cara menjaga kesehatan gigi dan mulut.

\section{DAFTAR PUSTAKA}

1. Budiharto, 2010, Ilmu Perilaku Kesehatan dan Pendidikan Kesehatan Gigi, EGC, Jakarta

2. Syamsul, BI. 2012. Prevalensi Karies Gigi Molar Pertama Permanen Pada murid - murid Sekolah Dasar di Kecamtan Tamalanrea. Jurnal e-GiGi $(e G)$, Volume 3, Nomor 2, Manado

3. Tarigan S, 2015, Karies Gigi, Hipocrates, Jakarta

4. Kementerian Kesehatan RI., 2012. Buku Panduan Pelatihan Kader Kesehaan Gigi dan Mulut di Masyarakat. Jakarta

5. Kementerian Kesehatan RI., 2013. Riset Kesehatan Dasar, Badan Penelitian \& Pengembangan Tenaga Kesehatan Kemenkes. Laksana, Jakarta

6. Notoatmojo, 2013, Promosi Kesehatan dan Ilmu Perilaku, Rineka Cipta, Jakarta

7. Kementerian Kesehatan RI., 2015: Pusat data dan Informasi, Jakarta

8. Sumerti, 2011, Faktor-faktor yang berhubungan dengan perilaku ibu dalam deteksi dini karies gigi pada balita di Kecamatan Kuta Utara Kabupaten Badung, Jurnal Kesehatan Gigi Vol.1No.1, Denpasar-Bali

9. Arini, N.W, Ratmini,N.K, Wirata I. N, Sirat N. M, 2018, Upaya 
Meningkatkan Derajat Kesehatan Gigi

Dan Mulut Melalui Pelatihan Kader

Posyandu Di Kecamatan Marga
Kabupaten Tabanan, Jurnal

Masyarakat Sehat, Vol.1 No.1

Denpasar-Bali 